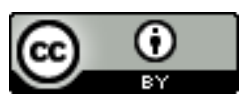

\title{
DEMOCRATIZAÇÃO DA EDUCAÇ̃̃o SUPERIOR BRASILEIRA: DO ACESSO AO COMPROMISSO COM O SUCESSO ACADÊMICO
}

\begin{tabular}{r}
\hline DEMOCRATIZATION OF BRAZILIAN HIGHER EDUCATION: \\
FROM THE ACCESS TO THE COMMITMENT TO ACADEMIC SUCCESS \\
\hline DEMOCRATIZACIÓN DE LA EDUCACIÓN SUPERIOR BRASILEÑA: \\
DEL ACCESO AL COMPROMISO CON EL ÉXITO ACADÉMICO \\
\hline Elisa Ustárroz '- \\
Sérgio Feldmann de Quadros \\
Marilia Costa Morosini
\end{tabular}

\begin{abstract}
RESUMO: O presente artigo parte da premissa de que, para além do compromisso com o acesso, a democratização da Educação Superior pressupõe um compromisso com o sucesso acadêmico dos estudantes. O que tem sido entendido por sucesso acadêmico no bojo do processo de democratização da Educação Superior é a pergunta que impulsiona a presente investigação. Objetiva-se desvelar alguns dos sentidos em que essa expressão tem sido empregada nos discursos dos diferentes atores que participam, direta ou indiretamente, no debate dos temas educacionais. Foram tomadas como objeto da análise, primeiramente, algumas produções acadêmicas sobre o tema e, em um segundo momento, os documentos da Conferência Nacional de Educação (CONAE) e os Planos Nacionais da Educação (PNE). O exame de tais documentos à luz das categorias emergentes - integralização curricular; vida universitária; competências; e cidadania - permitiu verificar que o sucesso acadêmico tem sido compreendido de maneira ampla, incorporando noções de, pelo menos, três das categorias. Integralização curricular, vida universitária e cidadania aparecem tanto na produção acadêmica quanto nos documentos analisados, o que nos faz pensar que estamos no caminho certo no que diz respeito a concepção de sucesso acadêmico que nos orienta. Resta saber quais são as ações políticas e estratégias institucionais que estão sendo efetivadas para criar oportunidades de sucesso para um maior número de estudantes, bem como a que concepção de sucesso tais ações políticas e estratégias institucionais estão vinculadas.
\end{abstract}

PALAVRAS-ChaVE: Sucesso acadêmico. Educação superior. Democratização. CONAE. PNE

ABSTRACT: This paper is based on the premise that, beyond the commitment to promoting access, the democratization of higher education also entails a commitment to the academic success of students. What has been understood by academic success in the process of democratization of Brazilian higher education is the question that drives this research, whose main purpose is to unveil some of the meanings with which this expression has been used in the discourses of different actors who participate, directly or indirectly, in the debate of educational issues. The academic production on this subject first, and the documents of the Brazilian National Conference of Education (CONAE) and the Brazilian Nationals Plans for Education (PNE) later have been taken as objects of analysis. The analyses of such documents in the light of the emerging categories - curricular integration, university life, competences and citizenship - has shown that academic success, in the process of democratization of Brazilian higher education, has been broadly understood by incorporating notions of at least three of the categories. Curricular integration, university life and citizenship appear both in the academic production and in the documents analyzed, which makes us think that we are on the right track concerning our framework. Which polices and institutional strategies have been performed to create opportunities of success for

Submetido em: 07/06/2017 - Aceito em: 21/07/2017 - Publicado em: 08/08/2017.

\begin{tabular}{|l|c|c|c|c|c|} 
(C) Rev. Inter. Educ. Sup. & Campinas, SP & v.3 & n.3 & p.539-561 & set./dez. 2017 \\
\hline
\end{tabular}


a greater number of students, as well as what kind of conception of success these polices and institutional strategies are bound by still remain to be understood.

KEYWORDS: Academic success. Higher education. Democratization. CONAE. PNE.

RESUMEN: El artículo parte de la premisa de que, además del compromiso con el acceso, la democratización de la Educación Superior presupone un compromiso con el éxito académico de los estudiantes. Lo que ha sido entendido por éxito académico en el seno del proceso de democratización de la Educación Superior es la pregunta que impulsa la investigación. Se pretende desvelar algunos de los sentidos en que esa expresión ha sido empleada en los discursos de los diferentes actores que participan, directa o indirectamente, en el debate de los temas educativos. Se tomaron como objeto del análisis, primero, algunas producciones académicas sobre el tema $\mathrm{y}$, en un segundo momento, los documentos de la Conferencia Nacional de Educación (CONAE) y los Planes Nacionales de Educación (PNE). El examen de estos documentos a la luz de las categorías emergentes integralización curricular; vida universitaria; competencias; y ciudadanía - permitió verificar que el éxito académico ha sido comprendido de manera amplia, incorporando nociones de al menos tres de las categorías. Integridad curricular, vida universitaria y ciudadanía aparecen tanto en la producción académica como en los documentos analizados, lo que nos hace pensar que estamos en el camino correcto en lo que concierne a la concepción de éxito académico que nos orienta. Es necesario saber, si bien, cuáles son las acciones políticas y estrategias institucionales que se están realizando para crear oportunidades de éxito para un mayor número de estudiantes, así como a qué concepción de éxito tales acciones políticas y estrategias institucionales están vinculadas.

PALABRAS CLAVE: Éxito académico. Educación superior. Democratización. CONAE. PNE.

\section{INTRODUÇÃ̃O}

Nas últimas décadas, não apenas no Brasil, mas em diversos países do mundo, tem sido verificada uma preocupação premente em democratizar a Educação Superior, criando-se oportunidades para uma parcela maior da população nesse nível educacional. Trata-se, efetivamente, de uma tendência, ou mesmo de uma necessidade, muitas vezes associada à controversa ideia da sociedade do conhecimento; outras, porém, associada à conquista de direitos. Essa orientação, contudo, traz significativos desafios que se relacionam, por certo, com a ampliação das oportunidades de acesso, mas não somente com ela, como é o caso da permanência dos estudantes e do sucesso acadêmico. Atentos a essas implicações, diversos pesquisadores do campo passaram a investigar as condições que impactam a permanência e o sucesso acadêmico dos estudantes da Educação Superior. Nesse contexto, as temáticas do acesso, da permanência e do sucesso acabaram por permear grande parte dos discursos educacionais.

Reconhecendo-se que o compromisso com a democratização da Educação Superior brasileira importa, para além da expansão do acesso, também a persecução do sucesso acadêmico, assume-se como objetivo do presente artigo identificar e analisar alguns dos sentidos em que a expressão sucesso acadêmico vem sendo empregada nos discursos de diferentes atores que participam, direta ou indiretamente, no debate dos temas educacionais. Enfoca, em especial,

\begin{tabular}{|l|c|c|c|c|c|} 
(C) Rev. Inter. Educ. Sup. & Campinas, SP & v.3 & n.3 & p.539-561 & set./dez. 2017 \\
\hline
\end{tabular}


possíveis projeções desses sentidos no que diz respeito à Educação Superior brasileira e sua democratização, permitindo a reflexão sobre sentidos mais apropriados a esta realidade.

Para tanto, na primeira seção, é situada a discussão, sendo retomado o fenômeno da democratização do acesso à Educação Superior e seus impactos sobre os campi universitários e as condições de permanência e sucesso acadêmico dos estudantes desse nível educacional. Na segunda seção, são tomados como objeto da análise produções acadêmicas, no intuito de identificar e compreender alguns dos diferentes sentidos que têm sido atribuídos à expressão sucesso acadêmico. Na terceira, à luz das categorias emergentes a partir da análise da produção acadêmica, são analisados os documentos produzidos pela Conferência Nacional de Educação (CONAE) e os Planos Nacionais da Educação (PNE). Ao final, apresenta-se as conclusões das análises, tomando em consideração o contexto educacional brasileiro e a necessidade de promoção de um sistema de educação terciária equitativo.

\section{A DEMOCRATIZAÇÃo do ACESSO À EDUCAÇÃo SUPERIOR NO BRASIL}

$\mathrm{O}$ acesso à Educação Superior no Brasil vem sendo progressivamente democratizado. Na década de 1990, a partir de políticas de viés neoliberal, a democratização foi impulsionada pela ampliação de ofertas de vagas no setor privado, como consequência tanto da desregulamentação desse nível educacional como da criação do Fundo de Financiamento Estudantil (FIES). A partir de 2002, não obstante tenha sido mantido o forte crescimento das Instituições de Ensino Superior (IES) privadas, o fortalecimento do setor público passou a concorrer também para o processo de democratização. As políticas dirigidas aos dois setores, nesse segundo período, foram marcadas por um forte cunho de inclusão social.

Dirigindo especial atenção às últimas duas décadas, é possível verificar um aumento considerável das vagas na Educação Superior brasileira tanto no setor público como no privado. Em 1992, havia 1,5 milhão de matrículas nesse nível educacional, das quais $41 \%$ eram em IES públicas e 59\% em IES privadas. Em 2013, o número aumentou para 7,3 milhões, sendo $26 \%$ nas públicas e $74 \%$ em IES privadas. Observa-se que o número de matrículas nas IES públicas neste período subiu de 630 mil para 1,93 milhão, o que representa um aumento de $210 \%$; enquanto, nas privadas, o número de matrículas subiu de 906 mil para 5,37 milhões, o que representa um aumento de 490\%. Tem-se, pois, que, no período considerado, o aumento do número de matrículas nas IES públicas foi de três vezes e nas IES privadas foi de quase seis vezes (INEP, 2002; 2013), o que denota que a ampliação foi bastante significativa neste período. 
Frisa-se que, embora as matrículas no setor público tenham aumentado, no setor privado cresceram duas vezes mais no período analisado. Associa-se o crescimento do setor privado à desregulamentação da Educação Superior brasileira, promovida na esteira da edição da Lei de Diretrizes e Bases da Educação Nacional (LDB) - Lei 9.394, de 20 de dezembro de 1996 (BRASIL, 1996) - e da implementação de outras políticas e ações voltadas aos interesses do setor. Nesse sentido, Cunha (2003) destaca dois exemplos emblemáticos: (a) a autonomia concedida pela LDB às universidades para abertura de cursos e para a definição dos processos seletivos; e (b) a constituição histórica do Conselho Nacional de Educação (CNE), antigo Conselho Federal de Educação, com a representação majoritária das entidades do setor privado. Não se pode deixar de considerar também, quando se pensa o crescimento do setor privado, o impacto de outras razões de ordem socioeconômicas como, por exemplo, o incremento do número de pessoas com ensino médio completo e a melhora da capacidade econômica das pessoas que as tornou aptas a ingressar em um curso superior e, de alguma maneira, a custear as despesas daí decorrentes ao longo de sua formação.

No âmbito do setor público, importante destacar a diferença do crescimento do número de matrículas entre os governos do Partido da Social Democracia Brasileira (PSDB), de Fernando Henrique Cardoso (1995-2002), e os governos do Partido dos Trabalhadores (PT), de Luiz Inácio Lula da Silva e Dilma Rousseff (2003-2016). Nos anos de governo do PSDB, o número de matrículas nas IES públicas aumentou de 700 mil para 1 milhão, sendo que nas federais esse aumento foi de 363 mil para 532 mil. Ressalta, contudo, Cunha (2003) que, nesse mesmo período, as IES federais estavam sofrendo com a falta de recursos. Nos dez anos do governo do PT (2003-2013), o número de matrículas nas IES públicas aumentou de 1,13 milhão para 1,93 milhão, sendo que nas federais o aumento foi mais significativo, de 567 mil para 1,13 milhão (INEP, 2000; 2002; 2013). Observa-se que não cabe avaliar o crescimento das instituições, uma vez que, em alguns momentos, foram integradas instituições diferentes e, em outros, desmembradas, o que não permite uma análise fidedigna dos dados.

O crescimento da Educação Superior brasileira apontado, seja por meio das matrículas no setor público, seja por meio das matrículas no setor privado, foi viabilizado por importantes políticas e programas voltados à essa área; e, a esse respeito, também pode se revelar oportuno destacar algumas distinções entre as promovidas pelos governos PSDB e PT.

Dentre as políticas e programas voltados à Educação Superior no governo do PSDB, além da desregulamentação da educação promovida pela LDB já citada, podemos destacar como a de maior importância a criação Fundo de Financiamento Estudantil (FIES), instituído pela Lei 10.260/2001, de 12 de julho de 2001 (BRASIL, 2001), no penúltimo ano do seu segundo mandato. Tal programa - ainda vigente - consiste na oferta de empréstimo, com os juros subsidiados pelo Estado, para as pessoas que queiram cursar a educação terciária em IES não 
gratuitas, em cursos com avaliação positiva no Sistema Nacional de Avaliação da Educação Superior (SINAES). Embora criado no governo do PSDB, o programa fortaleceu-se durante os governos posteriores, tendo sido redefinido pela Lei n. 12.202, de 14 de janeiro de 2010 (BRASIL, 2010). Durante o período de 2010 a 2015, a taxa de juros foi reduzida de $6,5 \%$ a.a. para 3,4\% a.a. Em 2015, entretanto, a taxa de juros voltou a ser cobrada nos mesmos percentuais do início do programa (AMORIN; BARROS, 2014).

Por sua vez, nos mandatos do governo do PT, podemos destacar um conjunto de políticas e programas voltadas prioritariamente à expansão das oportunidades de acesso à Educação Superior, mas que não deixaram de atentar para a questão da permanência dos estudantes, condição indispensável para o sucesso acadêmico.

No que diz respeito à oferta de vagas no âmbito das instituições privadas, além da ampliação do FIES, foi criado o Programa Universidade para Todos (PROUNI), instituído pela Lei ${ }^{\circ}$ 11.096/2005 (BRASIL, 2005). Tal programa visa ofertar bolsas de estudos, parciais e integrais, em cursos de graduação e sequenciais de formação específica para alunos de baixa renda em IES privadas. São elegíveis estudantes, egressos da rede pública ou da rede particular, previamente cadastrados no sistema de seleção informatizado, que leva em consideração as notas obtidas no ENEM e a condição socioeconômica do estudante. Como explica Carvalho (2005), o PROUNI teve origem em 2004 na burocracia do Ministério da Educação (MEC) como uma reação às demandas e pressões políticas do conjunto das IES privadas e das camadas sociais que estavam excluídas da Educação Superior. É possível pensá-lo como um programa que, embora tradicionalmente assumido como voltado à promoção do acesso, também favorece a permanência dos estudantes, na medida em que são concedidas bolsas de estudos que auxiliam a manutenção do aluno ao longo da formação universitária. Dessa forma, o programa foi delineado tendo como ponto de partida a concessão de bolsas de estudos por parte dos estabelecimentos particulares aos estudantes pobres, associado à adoção de políticas afirmativas e à melhoria na qualificação de professores da rede pública da educação básica. Em contrapartida, as instituições que aderiram ao programa, conforme regras específicas e diferenciadas de acordo com o modelo institucional, beneficiaram-se de renúncia fiscal (CARVALHO, 2005).

Já no que diz respeito a ampliação de vagas no setor público, é importante destacar duas políticas que ampliaram e interiorizaram a oferta de Educação Superior pública e gratuita: a Reestruturação e Expansão das Universidades Federais (REUNI) ${ }^{2}$, por meio do Decreto $\mathrm{n}^{\circ}$

\footnotetext{
${ }^{2}$ O Programa de Apoio a Planos de Reestruturação das Universidades teve por objetivo ampliar o acesso e a permanência na Educação Superior, de modo que todas as universidades federais aderiram ao programa e apresentaram ao MEC medidas diversas como a ampliação ou abertura de cursos noturno, aumento do número de alunos por professor, a redução do custo por aluno, a flexibilização do currículo, o combate à evasão dentre \begin{tabular}{l|l|l|l|r|} 
(C) Rev. Inter. Educ. Sup. & Campinas, SP & v.3 & n.3 & p.539-56
\end{tabular} set./dez. 2017
} 
6.096/2007 (BRASIL, 2007); e a criação dos Institutos Federais, por meio da Lei $\mathrm{n}^{0}$ 11.892/2008 (BRASIL, 2008).

Merece destaque, também, outra relevante iniciativa: a criação de política de ação afirmativa, baseada na discriminação positiva de grupos sociais minoritários e/ou desfavorecidos histórica e/ou socioeconomicamente por meio de cotas, através da Lei $\mathrm{n}^{0} 12.711$, de 29 de agosto de 2012 (BRASIL, 2012). A denominada Lei de Cotas estabelece que todas as IES federais vinculadas ao Ministério da Educação (MEC) deverão reservar, em cada concurso seletivo para ingresso nos cursos de graduação, por curso e turno, no mínimo, $50 \%$ das vagas para estudantes que tenham cursado integralmente o ensino médio em escolas públicas e que, no preenchimento destas vagas, 50\% (cinquenta por cento) deverão ser reservados aos estudantes oriundos de famílias com renda igual ou inferior a 1,5 salário-mínimo (um saláriomínimo e meio) per capita. Ainda, determina que cada IES reserve vagas para autodeclarados pretos, pardos e indígenas de acordo com a proporção de cada etnia na unidade federativa da instituição (BRASIL, 2012).

Nesse contexto, portanto, foram ampliadas as oportunidades de acesso à Educação Superior brasileira, seja pelo aumento e reserva de vagas nas IES públicas, seja pelo aumento de vagas, concessões de bolsas, integrais ou parciais, e empréstimos subsidiados para o acesso às IES privadas. No mesmo passo, o significativo aumento do número de matrículas neste nível educacional demonstra que efetivamente há demanda social por educação terciária no Brasil. Ainda, conforme observa Ristoff (2014, p. 726), se comparado com o crescimento do número de matrículas no ensino médio brasileiro - o qual correspondeu a $120 \%$ no mesmo período -, "o dado revela que a Educação Superior alimenta-se em grande parte com graduados de longa data, estudantes com mais de 24 anos, excluídos da Educação Superior por seu elitismo histórico".

Destarte, não seria demais admitir que as políticas públicas implementadas têm democratizado significativamente o acesso à Educação Superior ${ }^{3}$, de maneira que há em curso, no sistema de Educação Superior brasileiro, um aumento da proporção dos grupos

outros (BRASIL, 2007). A meta era dobrar o número de alunos nos cursos de graduação em dez anos, a partir de 2008, e permitir o ingresso de 680 mil alunos a mais nos cursos de graduação das Instituições Federais de Educação Superior (RISTOFF, 2014).

${ }^{3}$ Não obstante estejamos a afirmar que o acesso à educação terciária brasileira tenha sido democratizado, não desconhecemos que, a partir da classificação de Martin Trow, o nosso sistema ainda se caracterize como de elite e não como um sistema de massas. O sistema de acesso à Educação Superior brasileira somente será considerado um sistema de massas quando a taxa líquida de matrícula da população entre 18 e 24 anos nesse nível de ensino for elevada a 33\%, coincidindo com a meta 12 estipulada pelo Plano Nacional de Educação - PNE 2014-2024 (BRASIL, 2014). Atualmente os 7 milhões de estudantes matriculados nos cursos de graduação representam $15,1 \%$ da taxa líquida de escolarização e $28,7 \%$ da taxa bruta (RISTOFF, 2014). 
historicamente excluídos dos bancos universitários pela etnia, pela renda ou por ser egresso da rede pública de educação básica (RISTOFF, 2014). De fato, reputam-se a elas significativas mudanças nos perfis dos acadêmicos que hoje circulam pelos campi universitários.

Não obstante, se, por um lado, políticas dessa natureza certamente tem alguma aptidão para enfrentar e/ou compensar as dificuldades relacionadas ao acesso à Educação Superior, como já admitimos; por outro, são insuficientes no tratamento das desigualdades de capital cultural, renda, gênero e etnia que ainda se encontram enraizados na realidade social. Como consequência, novos desafios têm emergido, dentre os quais destacamos os relacionados à permanência e ao sucesso acadêmico dos estudantes.

Ocorre que os fatores que, ao longo dos cursos de graduação, condicionam a permanência e o sucesso acadêmico dos estudantes impactam de modo muito distinto os alunos de diferentes perfis e backgrounds educacionais (FELICETTI, CABRERA, MOROSINI, 2014). Se, no Brasil, até pouco tempo atrás, as preocupações estavam direcionadas quase que exclusivamente à ampliação do acesso à Educação Superior, o ingresso de novos públicos nas instituições que historicamente não os recebiam mudou as configurações destas e gerou novas demandas e preocupações, tais como a permanência e o sucesso, as quais vêm sendo crescentemente problematizadas.

De fato, pouco significa avançar a fim de permitir que mais alunos cheguem ao nível terciário, se depois há o abandono ou o insucesso. Firmar um compromisso com a democratização da Educação Superior brasileira significa mais do que permitir o acesso; significa viabilizar a permanência e o sucesso acadêmico.

Embora existam cada vez mais intelectuais, movimentos sociais, políticos e gestores educacionais preocupados com tais temáticas, considerando a polissemia inerente ao termo sucesso acadêmico, entende-se necessário, como condição para o firmar compromisso com a democratização da Educação Superior brasileira, compreender quais os sentidos têm sido a ele atribuídos. É o que se passa a intentar.

\section{ALGUNS SENTIDOS EXTRAÍdOS DA PRODUÇÃo ACADÊMICA}

Ao se proceder a revisão da literatura acerca da temática em questão, verifica-se que a mesma passou a ser foco da atenção de pesquisadores brasileiros e estrangeiros a partir da década de 1990, intensificando-se sobremaneira a partir da década de 2000.

Tais dados podem sugerir que o interesse pela temática do sucesso/insucesso acadêmico na

(C) Rev. Inter. Educ. Sup.

\begin{tabular}{l|l} 
Campinas, SP & v.3
\end{tabular}

n.3 p.539-561

set./dez. 2017 
Educação Superior tem acompanhado o crescente processo de democratização desse nível educacional. Como bem observa Alarcão (2000, p. 13), embora tomando o âmbito escolar como ponto de partida para as suas considerações:

Compreende-se facilmente a ausência desse discurso e dessa preocupação em tempos em que apenas uma pequena percentagem da população tinha acesso à educação [...] numa época em que as solicitações socioculturais eram reduzidas, as crianças e os jovens que frequentavam as escolas tinham motivações pessoais fortes e se inseriam em contextos sociais, familiares e escolares altamente favoráveis.

Pensando-se especificamente o âmbito da Educação Superior, entende-se que as mesmas razões podem ser a ele reconduzidas. Enquanto restrita a uma parcela minoritária e homogênea da sociedade, as condições que tais estudantes desfrutavam, fossem elas fruto da sua capacidade socioeconômica ou de seu capital cultural, favoreciam a permanência e o consequente sucesso acadêmico, de modo que nem um, nem outro, se colocavam como objeto de reflexão. Contudo, a medida em que o paradigma elitista da educação vai sendo transformado, problematizam-se as condições de permanência e de sucesso acadêmico, que passam, então, a receber atenção.

Diante da vasta produção acadêmica dos últimos 20 anos sobre o tema, optou-se por fazer uma revisão seletiva da literatura, pinçando, dentre as várias produções, algumas percebidas como mais ricas - por serem representativas de diferentes visões - para análise qualitativa realizada acerca dos sentidos extraídos da expressão sucesso acadêmico nos usos que dela tem sido feito. Assim, buscou-se produções que dessem conta de diferentes sentidos e contribuíssem para a emergência das categorias de análise. Ao final do processo, emergiram como categorias:

a) Integralização curricular: Nesta categoria, estão acolhidos aqueles sentidos mais restritos que identificam o sucesso acadêmico com os resultados positivos obtidos pelo estudante, seja por meio da aprovação nas disciplinas que conformam o currículo, da conclusão do curso de graduação ou da contemplação de suas metas acadêmicas e sociais. Podem- ser sintetizados por meio da ideia de aproveitamento dos estudos que permitem o avanço rumo à obtenção do grau. Segundo Kuh et al. (2006), trata-se de uma visão mais tradicional.

O sentido adotado por Silva (2010, p. 50-51) ilustra essa compreensão de sucesso como o resultado exitoso. Veja-se: "Ao falarmos de sucesso estamos nos referimos aos estudantes que conseguem trilhar a trajetória universitária até a conclusão do curso e sem interrupções que os levem ao prolongamento ou desistência da vida acadêmica". Nitidamente, o sentido adotado pela pesquisadora é um sentido restrito, que se relaciona a resultados exitosos colhidos pelo estudante conducente à integralização curricular. A adoção de uma definição

\begin{tabular}{|l|l|l|l|l|l|} 
(C) Rev. Inter. Educ. Sup. & Campinas, SP & v.3 & n.3 & p.539-561 & set./dez. 2017 \\
\hline
\end{tabular}


assim pode ser justificada pela maior facilidade de se medir o sucesso acadêmico.

Ainda nessa orientação, também pode-se indicar o sentido de sucesso acolhido por Seidman (2012), muito embora, além da conclusão do curso e colação do grau, o autor considere também a realização de metas individuais acadêmicas e sociais. Essas metas podem ter diferente natureza, mas, não obstante essa possibilidade que amplia em certa medida a compreensão de sucesso do autor, trata-se ainda assim de um enfoque no resultado: atingir ou não as metas, sendo a principal delas - conforme se pode extrair da leitura dos escritos do autor norte-americano - a conclusão do curso.

b) Vida universitária: Nessa categoria, reúnem-se sentidos de sucesso acadêmico um tanto mais complexos que o relacionam com as vivências dos alunos no ambiente universitário: suas expectativas, frustrações e superações, traduzidas como capacidade de adaptação ao ambiente universitário. Nessa perspectiva, o sucesso acadêmico teria algo de dinâmico, na medida em que não seria apenas um resultado a ser atingido ao final do curso com a conclusão do mesmo, mas um processo permanente relacionado à adaptação do aluno às características e às exigências que conformam o ambiente universitário em que está inserido e no qual deverá desenvolver suas capacidades. Diz com interação e integração.

Esse é o sentido adotado por Taveira (2000), para quem o sucesso acadêmico é a capacidade de adaptação e de desenvolvimento vocacional dos alunos no ambiente universitário. $\mathrm{O}$ sucesso acadêmico residiria, de tal forma, no bem adaptar-se ao ambiente universitário e com ele manter relações harmoniosas, o que também pode sugerir alguma relação com as próprias expectativas do aluno frente as suas vivências nesse nível educacional.

Os resultados escolares objetivos, notadamente, têm sua importância significativamente minimizada quando se emprega sucesso acadêmico no sentido em que o faz Taveira, que realça a importância da dimensão subjetiva, na esteira em que fazem outros pesquisadores da temática da permanência, tais como Tinto (1975) e Terenzini e Pascarella (1980).

Lencastre et al. (2000, p. 75), em posição semelhante, destacam a natureza multifacetada e subjetiva da definição conceitual de sucesso e explicam:

[...] multifacetada porque quando se fala em sucesso este nos remete para uma noção mais abrangente que tem a ver com a adaptação bem sucedida, e que avalia o sucesso não só no domínio académico mas também nos domínios sócio-relacional e biopsicológico. Subjectiva porque um mesmo desempenho pode ser percepcionado de forma diferentes dependendo dos objetivos do aluno. Assim o sucesso é concebido como a razão entre o que se pretende conseguir (objetivos) e o que efetivamente se conseguiu (resultados). 
O sentido extraído do termo sucesso a partir do emprego feito pelas autoras poderia denotar uma proximidade com o sentido extraído do texto de Taveira: ambos atentam para a adaptação, embora Lencastre et al. (2000) também incorporem um olhar para os resultados efetivamente conseguidos, confrontando-os com aqueles que o próprio estudante esperava conseguir. Deve-se observar, contudo, que, no excerto supracitado, as autoras estão a se referir ao sucesso na experiência universitária de modo amplo, o qual englobaria três diferentes domínios: a) o acadêmico (relacionado ao acesso e desempenho ao longo do ensino superior); b) o sócio-relacional (relacionado à inserção e adaptação no contexto universitário); e c) o biopsicológico (relacionado à saúde física e psicológica e, de modo mais amplo, com a própria qualidade de vida e bem-estar). Verifica-se, pois, que, para as autoras, o sucesso acadêmico, não obstante fortemente impactado pelos dois outros, conforme demonstram, representaria apenas um domínio do sucesso, sendo reduzido aos resultados obtidos pelo aluno nas disciplinas - dimensão objetiva - e ao grau de satisfação do aluno em relação a esses resultados - dimensão subjetiva. Sendo assim, a noção de sucesso com que trabalham as autoras é mais ampla, mas a de sucesso acadêmico reduzida a uma dimensão desse fenômeno.

c) Competências: Incluem-se, nesta categoria, sentidos relacionados ao desenvolvimento de competências técnicas e críticas, que permitirão ao estudante desde concretizar seus conhecimentos no campo prático-profissional até seguir aprendendo de forma autônoma. Trata-se de sentidos que, em certa medida, alinham-se com o assumido pela agência europeia Quality Assurance Agency for Higher Education e que partem da premissa de que nas sociedades atuais os egressos da Educação Superior precisam, mais do que conhecer o corpo de conhecimento que conforma as disciplinas de determinado campo, desenvolver competências técnicas analíticas e competências relacionadas à resolução de problemas que poderão ser utilizadas em diferentes atividades profissionais. Algumas dessas competências relacionadas ao sucesso acadêmico foram mapeadas nos estudos The Flexible Professional in the Knowledge Society - new demands on higher education in Europe (REFLEX - Europa ${ }^{4}$ ) e El professional flexible em la sociedade del conocimiento (PROFLEX - América Latina ${ }^{5}$ ).

Na pesquisa realizada por Dearnley e Matthew (2007, p. 378, tradução livre), o sucesso acadêmico relaciona-se com o "desenvolvimento de competências, de conhecimento e de motivação requeridas para a aprendizagem independente e autônoma ao longo da prática profissional". De certo modo, esse sentido de sucesso acadêmico favorece que os

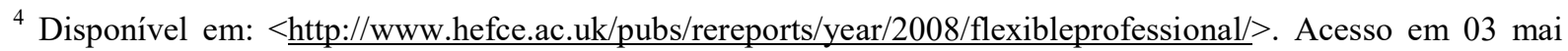
2017.

${ }^{5}$ Disponível em: <http://www.gestuniv.com.ar/gu_09/v3n3a2.htm>. Acesso em 03 mai 2017.

(C) Rev. Inter. Educ. Sup.

\begin{tabular}{l|l|l} 
Campinas, SP & v.3
\end{tabular} p.539-561

set./dez. 2017 
estudantes se tornem reflexivos sobre as suas práticas, na medida em que passam a perceber que eles próprios e suas experiências podem ser instrumentos para a sua formação e o desenvolvimento futuro de outras competências.

Deve-se cuidar, contudo, ao se adotar sentidos integrados nessa categoria para não associar o sucesso acadêmico exclusivamente às competências necessárias ao desempenho de diferentes atividades profissionais - competências técnicas -, visto que tal noção se aproximaria de uma visão utilitarista voltada ao mercado de trabalho. As competências críticas também são determinantes para um sentido rico de sucesso.

d) Cidadania: Esta categoria emergiu de sentidos que tomam o sucesso acadêmico para além de uma perspectiva individual, considerando também projeções sociais e comunitárias. Trata-se de um conceito mais compreensivo, alinhado a promoção da cidadania não apenas local, mas também global. Assume-se que tais sentidos se aproximam das orientações da UNESCO (2013) para a promoção de uma educação para a cidadania global, a qual compromete-se com a formação de cidadãos local e globalmente responsáveis e conscientes de valores tais quais o respeito pelos direitos humanos, a justiça social, a diversidade, entre outros significativos para a promoção de uma sociedade mais justa, equitativa e sustentável.

A definição de Tavares (2000, p. 8) ilustra bem os sentidos acolhidos nesta categoria:

Por sucesso acadêmico entendemos não apenas o sucesso escolar ou o educativo mas também o sucesso pessoal, social e comunitário que deverá atingir o estudante universitário durante o tempo da sua vida no interior da academia que não poderá ser medido, apenas, pelas classificações ou notas do seu rendimento escolar mas sobretudo pelo desenvolvimento de capacidades e competências relacionais, de discernimento, de iniciativa, de espírito crítico e de bom senso que lhe permitam depois, na sua actividade profissional, responder de um modo adequado e eficaz às mais variadas situações que a vida e a futura profissão lhe irão proporcionar.

Em outra oportunidade, o autor reforça essa noção compreensiva de sucesso acadêmico.

Não poderá, na realidade, ser medido apenas pelo rendimento escolar atingido nas diferentes disciplinas do seu plano de estudos e pelo nível mais ou menos elevado de suas classificações. Hoje, conta, sobretudo, o seu desenvolvimento integrado pessoal e social, o seu equilíbrio, o bom senso, a maturidade, a capacidade de criatividade e de desenvolver relações humanas entre pares e superiores hierárquicos e de ajudar a resolver tensões e conflitos em ambientes de trabalho [...] sucesso académico integra, por um lado, de alguma forma o sucesso familiar, escolar, educativo e, por outro, possibilita e potencializa o sucesso social, profissional, cultural, axiológico, numa palavra, humano. (TAVARES; SILVA, 2001, p. 150) 
Não há que se ter dúvidas, o sentido compreensivo construído por Tavares tem sua riqueza proporcional à sua complexidade. Não se trata apenas de medir resultados objetivos, tampouco enfocar o aspecto subjetivo, trata-se de um engrandecimento do humano - da pessoa - que se projeta em todas as suas relações, inclusive sociais e comunitárias.

Também nessa categoria pode ser incluído o sentido extraído da leitura de Formichella (2011), que, baseando-se no enfoque das capacidades de Amartya Sen, compreende o sucesso acadêmico através do incremento das capacidades, traduzidas como liberdades fundamentais para eleger livremente o estilo de vida que se deseja viver plenamente em sociedade. Para tanto, o estudante necessita se apropriar de um conjunto de conhecimentos e manifestar atitudes que lhes permitam exercitar essa liberdade de eleição de seu projeto de vida, dentre as quais, nas sociedades atuais, se destaca a capacidade contínua de aprendizagem.

A partir de tais contribuições extraídas da produção acadêmica que ilustram as diferentes compreensões do que é e pode ser compreendido por sucesso acadêmico, resta claro a ambiguidade da expressão e a necessidade de, ao adotá-la, explicitar em que sentido se faz. Passa-se, pois, a um exercício de explicitação e análise dos sentidos subjacentes aos documentos produzidos pela CONAE nos anos de 2010 e 2014 e aos PNEs, no marco da democratização da Educação Superior brasileira, à luz destas categorias emergentes.

\section{OS SENTIDOS EXTRAíd0S doS DISCURSOS DAS CONAES E DOS PNES}

No Brasil, a democratização/descentralização da educação é amplamente defendida por diversos segmentos da sociedade, ainda que também sobre os seus sentidos e significados não haja consenso. Estudo feito por Marques (2012, p 12) sobre possíveis sentidos da democratização da educação no Brasil destaca um especialmente relevante que diz com a participação dos cidadãos na tomada de decisões e, por consequência, com o aprofundamento da vida democrática. Veja-se:

(...) a democratização/descentralização da educação tem se colocado, na contemporaneidade, como fulcral nas políticas educacionais brasileiras, embora vinculada a projetos de sociedade diferenciados. Para uns a defesa da descentralização se fundamenta nos preceitos do liberalismo político, que reclamam instrumentos de proteção das liberdades individuais contra a ameaça de um Estado invasivo, enquanto que, para outros, essa nova forma de gestão dos assuntos estatais [com a gestão mais participativa realizada a partir do governo Lula/Dilma] favorece o aprofundamento da vida democrática, viabilizando a participação dos cidadãos nas decisões públicas (MARQUES, 2012, p. 1). 
A partir de 2003, com o início do governo do PT, passou-se, pois, a imprimir no âmbito educacional justamente essa perspectiva de gestão democrática, sendo impulsionada a criação de programas de fortalecimento dos conselhos escolares e de outros espaços participativos. No projeto daquele governo, três eixos foram tomados como prioritários: a) a democratização do acesso e a garantia de permanência; b) a qualidade social da educação; e c) a instauração do regime de colaboração e de democratização da gestão educacional (MARQUES, 2012). A Conferência Nacional de Educação (CONAE) insere-se nesta perspectiva.

A CONAE, realizada no ano de 2010 em Brasília, na esteira das conferências municipais, intermunicipais, distrital e estaduais precedentes, foi compreendida por seus integrantes profissionais da educação; estudantes; pais, mães e responsáveis por alunos; grupos organizados da sociedade civil; entidades de classes; e agentes públicos - como um acontecimento ímpar na história das políticas públicas do setor educacional no Brasil (CONAE, 2010). Concebida como um espaço que oportuniza a participação direta dos cidadãos para pautar suas demandas foi um dos relevantes instrumentos do governo do PT para a promoção do regime de colaboração e de democratização. A CONAE de 2010 expressamente indica o que entende por democratização da educação, ao ressaltar em seu Documento Final que:

a democratização da educação não se limita ao acesso à instituição educativa. $\mathrm{O}$ acesso é, certamente, a porta inicial para a democratização, mas torna-se necessário, também, garantir que todos os que ingressam na escola tenham condições de nela permanecer, com sucesso. Assim, a democratização da educação faz-se com acesso e permanência de todos no processo educativo, dentro do qual o sucesso escolar é reflexo da qualidade (CONAE, 2010, p.63, grifos do documento).

Nesse sentido, o Documento Final da CONAE 2010, que, posteriormente serviu de base para a consolidação do Plano Nacional de Educação (2014-2024), aprovado pela Lei no 13.005 , de 25 de junho de 2014, registra a necessidade de compromisso também com a permanência e com o sucesso, e, mais, explicita o que foi compreendido como sucesso. Estabelece que, para uma proposta de educação democrática e de qualidade, o sucesso não deve ser tomado apenas como o desempenho do aluno; ao contrário, deve ser considerado como garantia do direito à educação (CONAE, 2010).

Para a CONAE, uma trajetória escolar sem interrupções e o respeito ao desenvolvimento humano, à diversidade e ao conhecimento são alguns dos elementos-chave do sucesso, que deve ser perseguido através de "ações integradas que implicam a compreensão do fenômeno educativo na sua dimensão pedagógica, institucional, relacional, cultural e social" (CONAE, 2010, p. 63).

Ademais, a CONAE considera que o sucesso acadêmico implica condições dignas de trabalho, formação e valorização dos profissionais da educação, assim como reforça a

\begin{tabular}{l|l|l|l|l|l} 
(C) Rev. Inter. Educ. Sup. & Campinas, SP & v.3 & n.3 & p.539-561 & set./dez. 2017 \\
\hline
\end{tabular}


importância da construção democrática do Projeto Político Pedagógico (PPP) e do Plano de Desenvolvimento Institucional (PDI), por meio da participação da comunidade educativa e da escuta dos movimentos sociais. Certo é que as desigualdades sociais que se projetam sobre o acesso e a permanência dos estudantes devem ser conhecidas e levadas em conta na formulação de políticas, estratégias e práticas que visam a superação desse quadro e ao sucesso acadêmico dos estudantes, sob pena de que quando executadas venham a não lograr os fins pretendidos (CONAE, 2010).

Nesse sentido, sucesso acadêmico está indissociavelmente relacionado a uma educação democrática e de qualidade social, enquanto garantidor desse direito. Uma educação com tais atributos, por sua vez, envolveria a garantia ao "acesso ao conhecimento e ao patrimônio cultural historicamente produzido pela sociedade", à "construção de conhecimentos críticos e emancipadores a partir de contextos concretos" e à uma aprendizagem significativa que resulte "numa maior inserção cidadã e profissional ao longo da vida" (CONAE, 2010, p. 62$63)$.

Não há que se ter dúvidas, o conceito de sucesso daí decorrente é um conceito bastante compreensivo que se aproxima da categoria cidadania, visto que, para além do aspecto subjetivo individual, também considera projeções sociais e comunitárias.

Sintetizando, pode-se associar o sucesso acadêmico, segundo a CONAE de 2010, a três principais eixos:

a) Acesso a uma educação de qualidade social: pressupõe, segundo o documento, que os estudantes possam ter acesso a professores que desfrutem de condições dignas de trabalho e que sejam bem formados e devidamente valorizados; que sejam respeitados o desenvolvimento humano e a diversidade; que seja permitido acesso ao conhecimento e ao patrimônio cultural historicamente produzido pela sociedade; que os conhecimentos sejam críticos, emancipadores e construídos a partir de contextos concretos; que sejam vivenciadas situações de aprendizagem variadas que envolvam para além do ensino, atividades de pesquisa e extensão; que seja possibilitado o processo de continuidade dos estudos; que seja assegurada a inserção cidadã e profissional (CONAE, 2010).

b) Reconhecimento das desigualdades para o seu acesso e permanência: pressupõe devam ser identificados e tomados em consideração os pesos das desigualdades nos percursos formativos - sejam elas socioeconômica, étnico-racial de gênero, cultural e de acessibilidade - e criadas políticas de superação das mesmas de modo a garantir o acesso e as condições de permanência dos estudantes, a viabilizar uma trajetória educacional sem interrupções e a concretizar o direito a uma aprendizagem significativa. 
c) Participação nos processos de gestão: pressupõe a democratização dos conselhos e órgãos semelhantes já existentes; a abertura de novos espaços de participação dos cidadãos na tomada de decisões; a construção participativa do PPP e do PDI junto à comunidade educativa e aos movimentos sociais.

No documento resultante da CONAE de 2014, por outro lado, a temática do sucesso não recebeu o destaque que lhe foi dado na edição anterior. Não obstante, é possível afirmar que, ao assumir um posicionamento de forte cunho emancipatório, ressaltando o papel da educação na construção de um projeto de nação, como locus privilegiado da prática social e cultural, comprometeu-se com um sentido de sucesso como aqueles integrados na categoria cidadania.

No que se refere à democratização, a Conferência destacou a importância de políticas afirmativas de acesso e permanência na Educação Superior, em especial das políticas de cotas, assim como frisou a necessidade de um processo de expansão e de democratização orientado a superação das assimetrias regionais.

Sublinhe-se que essa CONAE demandou a garantia de moradia estudantil a todos os estudantes de IES públicas provenientes de outra cidade (CONAE, 2014), o que nos permite certa associação também à categoria vida universitária. Ainda que restrita a uma medida e àqueles estudantes deslocados de sua cidade, o fundamento que justifica tal preocupação é a adaptação do estudante ao ambiente universitário.

Embora apareça em alguns momentos o termo 'sucesso', esta Conferência procurou apresentar a 'equação' da democratização da educação como acesso, permanência, aprendizagem e conclusão. Apesar da edição anterior ter sido mais explícita nas referências ao sucesso, a concepção de sucesso que permeia ambas não parece diferir, podendo também essa ser reconduzida às categorias integralização curricular, vida universitária e cidadania. As ideias relacionadas à aprendizagem e à qualidade social da educação ainda permanecem, não obstante no documento anterior fossem melhor exploradas. Vale ressaltar que esta conferência tinha por intuito criar emendas ao PNE que estava por ser aprovado à época e, portanto, em grande medida, apenas reportou-se a questões sobre as quais já havia sido produzido consenso em 2010.

O Plano Nacional de Educação 2001-2010 pouco desenvolveu as questões relacionadas à democratização da Educação Superior, especialmente no que se refere permanência e ao sucesso. No tocante ao acesso, não há nele previsão de políticas de cotas. No que diz respeito à permanência, políticas de assistência estudantil não foram contempladas. A defesa, presente no item 19 dos objetivos e metas, é da criação de políticas de compensação das deficiências 
escolares para que os candidatos à Educação Superior possam competir em igualdade de condições.

No PNE 2014-2024, entretanto, três metas são destinadas à Educação Superior. A meta 12 trata da questão da democratização da educação na relação do ingresso de jovens de 18 a 24 anos e estabelece, para o prazo deste plano, que as matrículas desta população atinja $50 \%$ para a taxa bruta e 33\% da taxa líquida. As metas 13 e 14 enfocam a formação de mestres e doutores e sua proporção entre os professores da Educação Superior. Dentre as metas relacionadas ao sucesso - no mesmo sentido em que defendia a CONAE de 2010 -, a 12.3 prevê "elevar gradualmente a taxa de conclusão média dos cursos de graduação presenciais nas universidades públicas para 90\%" (BRASIL, 2014, s/p.). Nas estratégias para tal meta, aparecem questões relacionadas à mobilidade estudantil; acessibilidade; relação com pesquisa e extensão; inclusão e formação (com conclusão) da população do campo, quilombolas e indígenas; aprimoramento da qualidade através da melhora da infraestrutura; dentre outros fatores.

Merecem destaque também as estratégias determinadas para alcançar a meta 14, as quais enfocam questões relacionadas à melhoria e ao incentivo à pós-graduação strictu sensu, através de financiamento por meio do FIES, tanto para os próprios programas como para os estudantes. Outras estratégias também são formuladas em relação à mobilidade acadêmica, à superação das desigualdades étnicas-raciais e de gênero, entre outras.

Abaixo, apresenta-se uma síntese de duas demandas propostas pela CONAE 2010 - 'acesso a uma educação de qualidade social' e 'reconhecimento das desigualdades para o acesso e permanência' - e as metas e estratégias do PNE 2014-2024.

Quadro 1. Demandas da CONAE 2010 incorporadas no PNE 2014-2024 relacionadas ao sucesso acadêmico

\begin{tabular}{|c|c|c|}
\hline \multirow{2}{*}{ Fatores } & \multicolumn{2}{|c|}{ Meta (M)/Estratégia (E) } \\
\cline { 2 - 3 } & META 12 & META 13 \\
\hline \multirow{2}{*}{$\begin{array}{c}\text { E12.1: "Otimizar a capacidade instalada da } \\
\text { estrutura física e de recursos humanos das } \\
\text { instituições públicas de educação superior, } \\
\text { mediante ações planejadas e coordenadas, de forma } \\
\text { a ampliar e interiorizar o acesso à graduação" }\end{array}$} & $\begin{array}{c}\text { M13: "Elevar a qualidade da } \\
\text { educação superior e ampliar a } \\
\text { proporção de mestres e doutores do } \\
\text { corpo docente em efetivo exercício } \\
\text { no conjunto do sistema de educação } \\
\text { superior para 75\% (setenta e cinco } \\
\text { por cento), sendo, do total, no } \\
\text { mínimo, 35\% (trinta e cinco por } \\
\text { cento) doutores" }\end{array}$ \\
\cline { 2 - 3 } & $\begin{array}{c}\text { E12.7: "Assegurar, no mínimo, 10\% (dez por } \\
\text { cento) do total de créditos curriculares exigidos }\end{array}$ & $\begin{array}{c}\text { E13.5: "Elevar o padrão de } \\
\text { qualidade das universidades, }\end{array}$ \\
\hline
\end{tabular}




\begin{tabular}{|c|c|c|}
\hline \multirow{4}{*}{$\begin{array}{l}\text { Acesso a uma } \\
\text { educação de } \\
\text { qualidade social }\end{array}$} & $\begin{array}{l}\text { para a graduação em programas e projetos de } \\
\text { extensão universitária, orientando sua ação, } \\
\text { prioritariamente, para áreas de grande pertinência } \\
\text { social" }\end{array}$ & $\begin{array}{l}\text { direcionando sua atividade, de modo } \\
\text { que realizem, efetivamente, pesquisa } \\
\text { institucionalizada, articulada a } \\
\text { programas de pós-graduação stricto } \\
\text { sensu" }\end{array}$ \\
\hline & $\begin{array}{l}\text { E12.8: "Ampliar a oferta de estágio como parte da } \\
\text { formação na educação superior" }\end{array}$ & $\begin{array}{l}\text { E13.7: "Fomentar a formação de } \\
\text { consórcios entre instituições públicas } \\
\text { de educação superior, com vistas a } \\
\text { potencializar a atuação regional, } \\
\text { inclusive por meio de plano de } \\
\text { desenvolvimento institucional } \\
\text { integrado, assegurando maior } \\
\text { visibilidade nacional e internacional } \\
\text { às atividades de ensino, pesquisa e } \\
\text { extensão" }\end{array}$ \\
\hline & $\begin{array}{l}\text { E12.12: "Consolidar e ampliar programas e ações } \\
\text { de incentivo à mobilidade estudantil e docente em } \\
\text { cursos de graduação e pós-graduação, em âmbito } \\
\text { nacional e internacional, tendo em vista o } \\
\text { enriquecimento da formação de nível superior" }\end{array}$ & $\begin{array}{l}\text { E13.8: “(...) Fomentar a melhoria } \\
\text { dos resultados de aprendizagem, de } \\
\text { modo que, em } 5 \text { (cinco) anos, pelo } \\
\text { menos } 60 \% \text { (sessenta por cento) dos } \\
\text { estudantes apresentem desempenho } \\
\text { positivo igual ou superior a } 60 \% \\
\text { (sessenta por cento) no Exame } \\
\text { Nacional de Desempenho de } \\
\text { Estudantes - ENADE e, no último } \\
\text { ano de vigência, pelo menos } 75 \% \\
\text { (setenta e cinco por cento) dos } \\
\text { estudantes obtenham desempenho } \\
\text { positivo igual ou superior a } 75 \% \\
\text { (setenta e cinco por cento) nesse } \\
\text { exame, em cada área de formação } \\
\text { profissional” }\end{array}$ \\
\hline & $\begin{array}{l}\text { E12.21: "Fortalecer as redes físicas de laboratórios } \\
\text { multifuncionais das IES e ICTs nas áreas } \\
\text { estratégicas definidas pela política e estratégias } \\
\text { nacionais de ciência, tecnologia e inovação" }\end{array}$ & \\
\hline & $\begin{array}{l}\text { E12.3: "Elevar gradualmente a taxa de conclusão } \\
\text { média dos cursos de graduação presenciais nas } \\
\text { universidades públicas para 90\% (noventa por } \\
\text { cento), ofertar, no mínimo, um terço das vagas em } \\
\text { cursos noturnos e elevar a relação de estudantes } \\
\text { por professor (a) para } 18 \text { (dezoito), mediante } \\
\text { estratégias de aproveitamento de créditos e } \\
\text { inovações acadêmicas que valorizem a aquisição } \\
\text { de competências de nível superior" }\end{array}$ & $\begin{array}{l}\text { E13.8: "Elevar gradualmente a taxa } \\
\text { de conclusão média dos cursos de } \\
\text { graduação presenciais nas } \\
\text { universidades públicas, de modo a } \\
\text { atingir } 90 \% \text { (noventa por cento) e, } \\
\text { nas instituições privadas, } 75 \% \\
\text { (setenta e cinco por cento) (...)" }\end{array}$ \\
\hline & $\begin{array}{l}\text { E12.5 :“Ampliar as políticas de inclusão e de } \\
\text { assistência estudantil dirigidas aos (às) estudantes } \\
\text { de instituições públicas, bolsistas de instituições } \\
\text { privadas de educação superior e beneficiários do } \\
\text { Fundo de Financiamento Estudantil - FIES, de que } \\
\text { trata a Lei no 10.260, de } 12 \text { de julho de } 2001 \text {, na } \\
\text { educação superior, de modo a reduzir as } \\
\text { desigualdades étnico-raciais e ampliar as taxas de } \\
\text { acesso e permanência na educação superior de }\end{array}$ & \\
\hline
\end{tabular}




\begin{tabular}{|c|c|}
\hline $\begin{array}{l}\text { Reconhecimento } \\
\text { das } \\
\text { desigualdades } \\
\text { para o seu acesso } \\
\text { e permanência }\end{array}$ & $\begin{array}{c}\text { estudantes egressos da escola pública, } \\
\text { afrodescendentes e indígenas e de estudantes com } \\
\text { deficiência, transtornos globais do } \\
\text { desenvolvimento e altas habilidades ou } \\
\text { superdotação, de forma a apoiar seu sucesso } \\
\text { acadêmico" (s/p. grifos nossos) }\end{array}$ \\
\hline & $\begin{array}{l}\text { E12.9: "Ampliar a participação proporcional de } \\
\text { grupos historicamente desfavorecidos na educação } \\
\text { superior, inclusive mediante a adoção de políticas } \\
\text { afirmativas, na forma da lei”" }\end{array}$ \\
\hline & $\begin{array}{c}\text { E12.10: “Assegurar condições de acessibilidade } \\
\text { nas instituições de educação superior, na forma da } \\
\text { legislação" }\end{array}$ \\
\hline & $\begin{array}{l}\text { E12.13: "Expandir atendimento específico a } \\
\text { populações do campo e comunidades indígenas e } \\
\text { quilombolas, em relação a acesso, permanência, } \\
\text { conclusão e formação de profissionais para atuação } \\
\text { nessas populações" }\end{array}$ \\
\hline & $\begin{array}{l}\text { E12.15: "Institucionalizar programa de } \\
\text { composição de acervo digital de referências } \\
\text { bibliográficas e audiovisuais para os cursos de } \\
\text { graduação, assegurada a acessibilidade às pessoas } \\
\text { com deficiência" }\end{array}$ \\
\hline
\end{tabular}

Fonte: Autores, dados do PNE, BRASIL, 2014, s/p.

Quanto ao terceiro item demandado, 'participação nos processos de gestão', salienta-se que o PNE faz exigências em relação a democratização da gestão da educação básica, mas é omisso em relação aos processos de gestão da Educação Superior, mesmo que muito defendido pela CONAE.

O sucesso, portanto, contido nos documentos produzidos pelas duas conferências nacionais de educação e nos PNEs, tem sido entendido de modo compreensivo. A conclusão sem interrupções e dentro do período previsto; a qualidade da educação; a superação das desigualdades étnicas, de gênero, geográficas, de classe, de acessibilidade e de percursos escolares; a relação entre a tríade do ensino-pesquisa-extensão; a aprendizagem por meio do acesso ao conhecimento historicamente produzido; e, a mobilidade estudantil foram questões encontradas que se relacionam ao sucesso segundo estes documentos. Deste modo, entende-se que contempladas pelo menos três categorias: integralização curricular, vida acadêmica e cidadania.

Frise-se que não foi possível identificar sentidos mais diretamente relacionados à categoria competência, o que pode demonstrar certo distanciamento com questões mais prementes do mundo do trabalho. Trata-se de um dado que merece ser objeto de reflexão. 


\section{CONSIDERAÇÕES FINAIS}

O compromisso com a democratização da Educação Superior não pode se limitar à ampliação das oportunidades de acesso a esse nível educacional; deve incorporar também o incremento do sucesso acadêmico vinculado à qualidade da Educação Superior. Para tanto, é fundamental compreender com que sucesso acadêmico deve a Educação Superior brasileira se comprometer.

Trata-se tão somente de se comprometer com que os alunos que hoje ingressam nesse nível educacional concluam os seus cursos? A conclusão de um curso, por certo, representa ganhos pessoais e sociais; mas é suficiente?

Verificou-se que os entendimentos acerca do sucesso acadêmico tomam direções diferentes, sobretudo em razão das visões de mundo que os sujeitos que os empregam compartilham e que lhes são, portanto, subjacentes. Isso não importa, contudo, dizer que essas diferentes direções sejam incompatíveis entre si. Dentro das análises aqui empregadas, três categorias apareceram em comum tanto nas produções acadêmicas quanto nos documentos resultantes das CONAEs e nos Planos Nacionais de Educação: a integralização curricular, a vida acadêmica e a cidadania. A categoria competência não foi diretamente contemplada, o que abre espaço para reflexões.

Partindo do princípio de que para a democratização da educação - processo integrado em um contexto geral de democratização da própria sociedade brasileira - é necessária uma busca por maior igualdade de oportunidades, acredita-se que a conclusão do curso sem interrupções é certamente um primeiro passo a ser dado - integralização curricular. Não obstante, outros elementos devem ser considerados, dentre os quais: uma aprendizagem que seja reflexo de uma educação de qualidade social; um compromisso com um ensino articulado com a pesquisa e com a extensão, que satisfaça as expectativas dos estudantes, da comunidade científica e da sociedade; uma vivência acadêmica saudável do ponto de vista sócio-relacional e biopsicológico, que favoreça o desenvolvimento humano e em que as desigualdades étnicas, geográficas, de gênero, de classe, de acessibilidade e de percursos escolares não sejam obstáculos - elementos da categoria vida acadêmica. Ainda, se destacam também as questões relacionadas a uma formação sustentada em conhecimentos, habilidades e atitudes que promovam a autonomia necessária não apenas para o ingresso e permanência no mundo do trabalho e para o exercício da cidadania ativa, mas também para o desenvolvimento contínuo da própria pessoa na condição de membro de uma comunidade e o incremento de suas capacidades - cidadania. 
Todos esses elementos devem conformar o sentido de sucesso com o qual entendemos que deve a Educação Superior brasileira se comprometer.

A partir da análise dos documentos neste artigo considerados, parecemos estar no caminho certo no que diz respeito à concepção de sucesso acadêmico nos orienta. Resta, contudo, saber quais são as ações políticas e estratégias institucionais que estão sendo efetivadas para dar conta das metas que foram propostas, bem como seus pressupostos e resultados, afim de compreender se está sendo perseguido e realizando na prática o sucesso acadêmico em sua concepção multifacetada.

\section{REFERÊNCIAS}

ALARCÃO, Isabel. Para uma conceptualização dos fenómenos de insucesso/sucesso escolares no ensino superior. In: TAVARES, José; SANTIAGO, Rui A., Ensino superior: (in)sucesso académico, Porto: Porto Editora, p. 13-23, 2000.

AMORIN, Lucas; BARROS, Daniel. Um intruso entre os maiores. Revista Exame. São Paulo, v.48, n. 13, p. 32-43, jul. 2014.

BRASIL. Decreto no 6.096, de 24 de abril de 2007. Diário Oficial da União: Seção 1, Brasília, DF, ano 144, n. 79, p. 7, 25 abr. 2007.

BRASIL. Lei n. 10.260, de 12 de julho de 2001. Diário Oficial da União: Seção 1, Brasília, DF, ano 138, n. 135, p. 2-4, 13 jul. 2001.

BRASIL. Lei n. 11.096, em 13 de janeiro de 2005. Diário Oficial da União: Seção 1, Brasília, DF, ano 142, n. 10, p. 7, 14 jan. 2005.

BRASIL. Lei n. 11.892, de 29 de dezembro de 2008. Diário Oficial da União: Seção 1, Brasília, DF, ano 145, n. 253, p. 1-3, 30 dez. 2008.

BRASIL. Lei n. 12.202, de 14 de janeiro de 2010. Diário Oficial da União: Seção 1, Brasília, DF, ano 147, n. 10, p. 3-4, 15 jan. 2010.

BRASIL. Lei n. 12.711, de 29 de agosto de 2012. Diário Oficial da União: Seção 1, Brasília, DF, ano 149, n. 169, p. 1-2, 30 ago. 2012.

BRASIL. Lei n. 13.005, de 25 de junho de 2014. Diário Oficial da União: Seção 1, Brasília, DF, ano 151, n. 120-A , p. 1-7, 26 jun. 2014.

BRASIL. Lei n. 9.394, de 20 de dezembro de 1996. Diário Oficial da União: Seção 1, Brasília, DF, ano 134, n. 248, p. 1, 23 dez. 1996. 
CARVALHO, Cristina Helena Almeida de. Uma análise crítica do financiamento do PROUNI: instrumento de estímulo à iniciativa privada e/ou democratização do acesso à Educação Superior? In: REUNIÃO ANUAL DA ANPED, 28., 2005: Caxambú. [Anais...]. Caxambú: Anped, 2005.

CONAE. Conferência Nacional de Educação. Documento final. Brasília, 2010.

CONAE. Conferência Nacional de Educação. Documento final. Brasília, 2014.

CUNHA, Luiz Antônio. O ensino superior no octênio FHC. Educ. Soc., Campinas, vol 24, n. 82. P. 37-61, abr, 2003.

DEARNLEY, Christine; MATTHEW, Bob. Factors that contribute to undergraduate student success. Teaching in Higher Education, v. 12, n. 3, jun, 2007, p. 377-391.

FELICETTI, Vera Lúcia; CABRERA, Alberto F.; MOROSINI, Marília Costa. Alumno Prouni: El impacto en la institución de educación superior y en la sociedad. Revista Iberoamericana de Educación Superior, v. 5, n. 13, p. 21-39, 2014.

FORMICHELLA, María Marta. Análisis del concepto de equidade educativa a luz del enfoque de las capacidades de Amartya Sen. Educación, v. 35, n. 1, p. 1-36, 2011.

KUH, George D.; KINZIE, Jillian; BUCKLEY, Jennifer A. et al. What Matters to Student Success: A Review of the Literature. Washington: National Center for Educational Statistics, 2006. Disponível em: <https://nces.ed.gov/npec/pdf/kuh_team_report.pdf > Acesso em: 10 dez. 2016.

LENCASTRE, Leonor; GUERRA, Marina Prista; LEMOS, Marina Serra de; PEREIRA, Duarte Costa. Adaptação dos alunos do primeiro ano das licenciaturas da Faculdade de Ciências da Universidade do Porto. In: TAVARES, José; SANTIAGO, Rui A., Ensino Superior: (in)sucesso académico, Porto: Porto Editora, p. 75-106, 2000.

MARQUES, Luciana R. Sentidos hegemônicos da democracia nas políticas de democratização: descentralização da educação. In.: CONGRESSO IBERO AMERICANO DE POLÍTICA E ADMINISTRAÇÃO DA EDUCAÇÃO, 3., 2012: Zaragoza. [Anais..]. Zaragoza: ANPAE, 2012. Disponível em:

<http://www.anpae.org.br/iberoamericano2012/Trabalhos/LucianaRosaMarques_res_int_GT7 .pdf $>$. Acesso em 26 de nov. 2016.

INEP. Instituto Nacional de Estudos e Pesquisas Educacionais Anísio Teixeira. Evolução do Ensino Superior - Graduação 1980-1998. Brasília, DF: 2000. Disponível em: <http://download.inep.gov.br/download/censo/1998/superior/evolucao_1980-1998.pdf>. Acesso em: 24 jul 2015. 
INEP. Instituto Nacional de Estudos e Pesquisas Educacionais Anísio Teixeira. Censo da Educação Superior - Resumo técnico. Brasília, DF: 2002. Disponível em: <http://download.inep.gov.br/download/censo/1998/superior/evolucao_1980-1998.pdf >. Acesso em: 24 jul 2015.

INEP. Instituto Nacional de Estudos e Pesquisas Educacionais Anísio Teixeira. Censo da Educação Superior. Brasília, DF: 2013. Disponível em:

<http://download.inep.gov.br/educacao_superior/censo_superior/apresentacao/2014/coletiva_ censo_superior_2013.pdf >. Acesso em: 24 jul 2015.

RISTOFF, Dilvo Ilvo. O novo perfil do campus brasileiro: uma análise do perfil socioeconômico do estudante de graduação. Avaliação, Sorocaba, v. 19, p. 723-747, 2014.

SAIDMAN, Alan. Introduction. In: SAIDMAN, Alan. College student retention: Formula for Student Success. 2.ed. Maryland: Rowman \& Littlefield Publishers, Inc., 2012.

SILVA, Neide Menezes. Sucesso e insucesso na educação superior: as representações sociais dos estudantes do centro acadêmico do agreste/UFPE. 2010. Dissertação (Mestrado) Universidade Federal de Pernambuco, Recife 2010.

TAVARES, José. Prefácio In: TAVARES, José; SANTIAGO, Rui A., Ensino superior: (in)sucesso académico, Porto: Porto Editora, p.7-10, 2000.

TAVARES, José; SILVA, Isabel Huet. Sucesso Acadêmico no Ensino Superior: In: SOUZA, R. Bruno de et al. (Org.). Análise do sucesso e insucesso na Universidade Técnica de Lisboa (UTL). III Simpósio Pedagogia na Universidade. Lisboa, 2001.

TAVEIRA, Maria do Céu. Sucesso no ensino superior: uma questão de adaptação e de desenvolvimento vocacional. In: TAVARES, José; SANTIAGO, Rui A., Ensino Superior: (in)sucesso académico, Porto: Porto Editora, p. 51-71, 2000.

TERENZINI, Patrick T.; PASCARELLA, Ernest T. Student/faculty relationships and freshman year educational outcomes: a further investigation. Journal of College Student Personnel, v. 21, p.521-528, 1980.

TINTO, Vincent. Dropout from Higher Education: a theoretical synthesis of recent research. Review of Educational Research, v.45, p.89-125, 1975.

UNESCO. Global citizenship education: an emerging perspective: outcome document of the Technical Consultation on Global Citizenship Education. Paris, 2013. 


\section{${ }^{\mathrm{i}}$ Sobre os autores}

\section{Elisa Ustárroz.}

E-mail: elisaustarroz@gmail.com / ORCID: http://orcid.org/0000-0001-7340-0660

Pontifícia Universidade Católica do Rio Grande do Sul - Brasil

Doutoranda em Educação pela Pontifícia Universidade Católica do Rio Grande do Sul [PUC-RS]

Sérgio Feldmann de Quadros

E-mail: sergiofquadros@ gmail.com / ORCID: http://orcid.org/0000-0002-8917-1011

Universidade Estadual de Campinas - Brasil

Mestrando em Educação pela Faculdade de Educação da Universidade Estadual de Campinas

[UNICAMP]

Marilia Costa Morosini

E-mail: marilia.morosini@pucrs.br / ORCID: http://orcid.org/0000-0002-2433-5783

Pontifícia Universidade Católica do Rio Grande do Sul - Brasil

Doutora em Educação pela Universidade Federal do Rio Grande do Sul [UFRGS] 